\title{
PESCA ASSOCIADA ENTRE GOLFINHOS E AVES MARINHAS ${ }^{1}$
}

\author{
Emygdio L. A. Monteiro-Filho ${ }^{2}$
}

\begin{abstract}
FEEDING ASSOCIATIONS BETWEEN DOLPHIN AND SEA BIRDS. Along ten years of study of a common dolphin from the brazilian coast, Sotalia brasiliensis Van Beneden, 1874, I could see some occasions of feeding associations of this dolphin with five species of birds, Sula leucogaster (Boddaert, 1783), Fregata magnificens Mathews, 1914, Sterna hirundinacea Lesson, 1831, Larus dominicanus Lichtenstein, 1823 and Phalacrocorax olivaceus Humboldt, 1895. The commonest association observed was between the dolphin and $\mathbf{S}$. leucogaster, and in all the associations was characterized the commensalism, with advantaged to the birds.
\end{abstract}

KEY WORDS. Sotalia, Cetacea, sea birds, feeding, behaviour

Estudos envolvendo associações com cetáceos são comuns quando relatam conflitos que levam a danos aos equipamentos de pesca (ver EVANS, 1987) e à disputa por peixes em determinados sítios (GASKIN et al., 1985), ou pesca cooperativa com pescadores de uma determinada região (LAMB, 1954; MOTEIRO-FILHO, em preparação).

Entretanto, há um outro tipo de associação que é registrado com pouca freqüência e que ocorre entre cetáceos e aves marinhas. Tal associação pode ser interpretada em alguns casos como mutualismo e em outros como comensalismo. No primeiro, as aves se beneficiam de um cardume localizado inicialmente por golfinhos ao passo que outros golfinhos se beneficiam pela intensa atividade das aves durante a pesca, para também localizarem o cardume (WÜRSIG \& WÜRSIG, 1979). No comensalismo, somente as aves se beneficiam, utilizando-se do cardume localizado pelos golfinhos (MARTIN, 1986).

No Brasil particularmente, onde são raros os estudos sobre cetáceos, não há informações sobre este tipo de associação. Desta forma, a proposta deste estudo é registrar a interação que ocorre com certa freqüência entre um golfinho comum no sudeste e sul do Brasil e algumas espécies de aves marinhas.

1) Contribuição número 774 do Departamento de Zoologia, Universidade Federal do Paraná.

2) Departamento de Zoologia, Universidade Federal do Paraná, Caixa Postal 19020, 81531-970 Curitiba, Paraná, Brasil. 


\section{MATERIAL E MÉTODOS}

\section{ÁREA DE ESTUDOS}

O local onde este estudo foi realizado, corresponde a um pequeno trecho do Complexo Estuarino-Lagunar de Cananéia, que se localiza no sul do Estado de São Paulo (de $25^{\circ} 02^{\prime}$ a $25^{\circ} 04^{\prime}$ S e 47 $54^{\prime}$ a 47 $56^{\prime}$ W; Fig. 1).

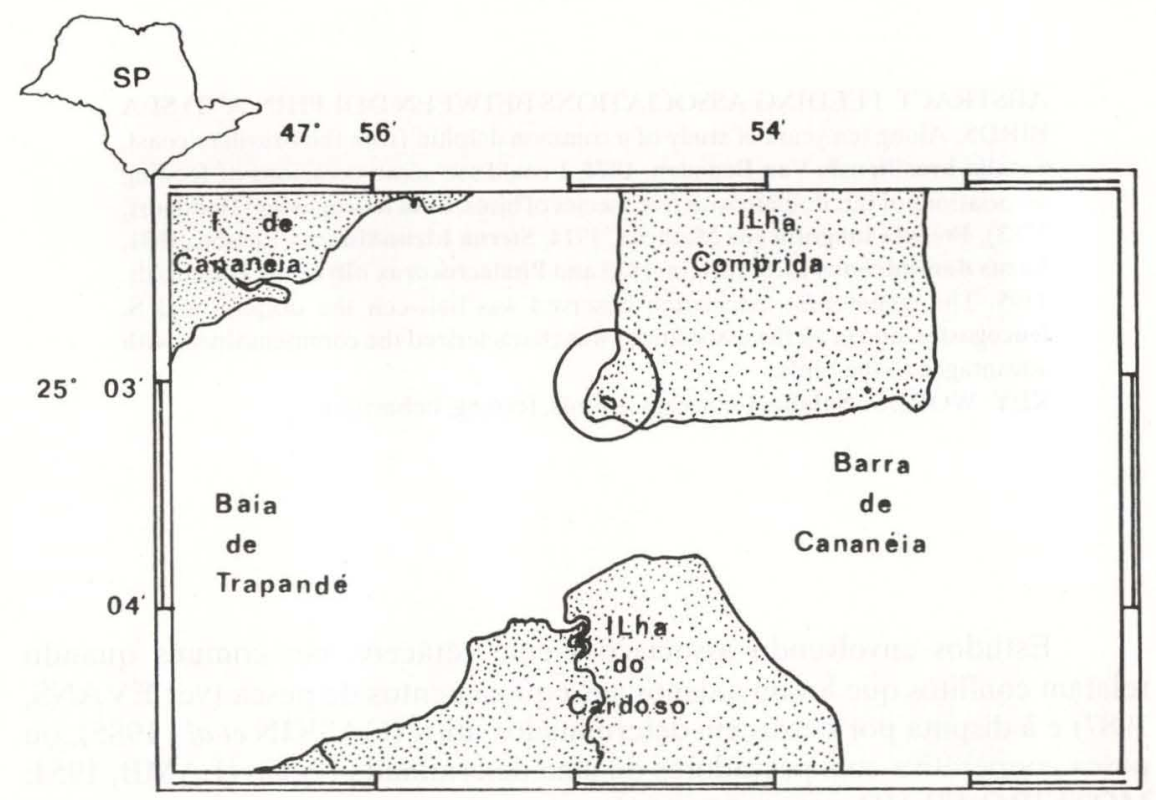

Fig. 1. Setor do Complexo Estuarino-Lagunar de Cananéia (litoral sul do Estado de São Paulo), onde foram realizadas as observações entre os golfinhos $\mathbf{S}$. brasiliensis e as cinco espécies de aves marinhas. A área do círculo corresponde à praia chamada Ponta da Trincheira.

Fisionomicamente, a região é caracterizada por apresentar um extenso canal marinho denominado Mar Pequeno, que situa-se entre a Ilha de Cananéia e a Ilha Comprida e também parte da Baía de Trapandé, que separa as ilhas acima citadas da Ilha do Cardoso.

No setor estudado, o canal possui largura variável de $460 \mathrm{~m}$ até $1500 \mathrm{~m}$ e profundidade máxima de $17 \mathrm{~m}$, ao passo que a baía tem largura variando entre $1900 \mathrm{~m}$ e $3700 \mathrm{~m}$, com profundidade que vai até $22 \mathrm{~m}$ (DHN, 1987).

\section{METODOLOGIA}

As observações dos comportamentos de pesca associativa executados entre os golfinhos e as aves marinhas na região de Cananéia foram feitas sempre na área de confluência do Mar Pequeno com a Baía de Trapandé, à bordo de uma embarcação ou até mesmo da Ponta da Trincheira, uma das poucas praias da região (Fig. 1). 
Para as observações que foram feitas com auxílio de binóculos, utilizei basicamente o método de amostragem seqüencial(quando o foco é uma série de comportamentos apresentados por um ou mais indivíduos) e raras amostragens do animal focal (quando um indivíduo é o foco das observações, cf. LEHNER, 1979). Posteriormente, foram feitas descrições funcionais (descrição que incorpora referência à função, cf. LEHNER, 1979) dos comportamentos observados.

Serão descritos inicialmente as estratégias utilizadas pelos golfinhos e posteriormente as utilizadas pelas aves marinhas com as respectivas associações.

Com o intuito de analisar a freqüência com que as diferentes espécies de aves se associavam aos golfinhos, utilizei o teste de Chi-quadrado $\left(\mathrm{X}^{2}\right)$.

\section{RESULTADOS}

Ao longo de um período de 10 anos de estudos comportamentais dos golfinhos Sotalia brasiliensis Van Beneden, 1874, na região de Cananéia, pude registrar alguns períodos de associações entre estes golfinhos e cinco espécies de aves marinhas da região: atobás [Sula leucogaster (Boddaert, 1783)], fragatas (Fregata magnificens Mathews, 1914), trinta-réis (Sterna hirundinacea Lesson, 1831), gaivotas (Larus dominicanus Lichtenstein, 1823) e biguás (Phalacrocorax olivaceus Humboldt, 1895).

As interações se davam sempre que os golfinhos realizavam as seguintes estratégias de caça:

1) Caça cruzada (Fig. 2a). Na presença de um cardume, uma formação familiar de golfinhos (casal adulto podendo ou não estar com o filhote) inicia uma seqüência de mergulhos, geralmente pouco profundos. No início os mergulhos são sempre no mesmo sentido, depois são feitos de tal forma que as trajetórias se cruzem (mergulho cruzado), mantendo o cardume dentro da área de cruzamento dessas trajetórias. Pode haver a participação do filhote, o qual segue com os adultos ou até mesmo um sub-adulto, que poderá atuar como um filhote jovem ou independentemente.

2) Caça em pequenos grupos (Fig. 2b). Ocorre quando cardumes de presas são localizados por uma formação familiar de golfinhos (estando ou não com filhote) e com sua atividade de caça, atrai a presença de uma segunda formação familiar, ou quando duas famílias cruzam suas trajetórias e permanecem associadas em períodos que podem durar até cerca de cinco minutos. A tática utilizada é semelhante à anterior, entretanto a caça cruzada não é feita entre os indivíduos, mas sim entre as formações familiares.

3) Caça em grandes grupos (Fig. 2c). Observada somente em ocasiōes quando há presença de grandes cardumes de presas. Ao encontrar um grande cardume, a atividade de caça de uma formação familiar de golfinhos é aumentada, atraindo para a área novas formações familiares que se deslocam em direção ao mesmo cardume. A associação das formações familiares leva à formação de um grande grupo, tendo sido observado até cerca de 30 indivíduos 


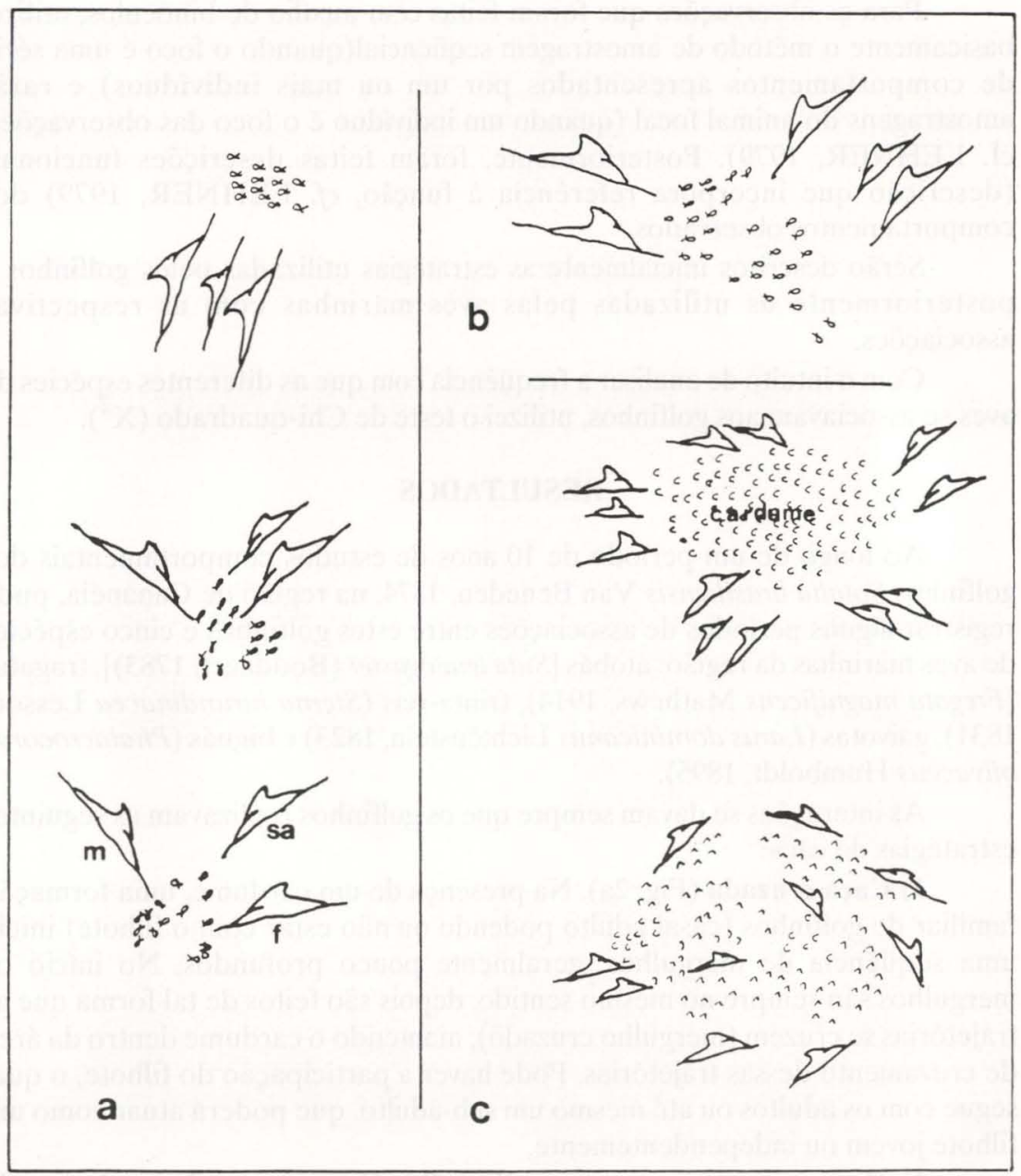

Fig. 2. Estratégias comportamentais executadas por $\mathbf{S}$. brasiliensis durante a caça. (a) Caça cruzada (m: macho, f: fêmea, sa: sub-adulto); (b) caça em pequenos grupos; (c) caça em grandes grupos.

que permanecem em torno do cardume, cercando-o. Não ocorre caça cruzada como nos pequenos grupos. Durante este cerco, alguns indivíduos iniciam persequições e mergulhos em direção ao centro do cardume, enquanto os demais permanecem em mergulhos profundos e pouco profundos na periferia, mantendo o cardume coeso.

Quanto às aves, apesar do número de indivíduos nas associaçōes ter variado bastante de uma espécie para outra, a freqüência com que se associavam aos golfinhos não apresentou diferença significativa entre as cinco espécies $\left(X^{2}=8,65 ;\right.$ g.l. $\left.=4 ; 0,10>P>0,05\right)$. Os tempos de associação também variaram, 
indo de cerca de um minuto até 50 minutos dependendo da espécie e da estratégia utilizada.

Atobá. São encontrados o ano todo e em maiores bandos, foi onde o número de indivíduos participantes variou de um a aproximadamente 30 indivíduos.

Grupos pequenos, com até cinco atobás associavam-se à qualquer uma das três estratégias já descritas para os golfinhos. Os encontros eram aparentemente casuais, visto que se davam sempre que os atobás deslocavam-se pela região em vôos a baixa altitude (até 10 metros), passando pela área onde os golfinhos forrageavam. Nestes encontros, os atobás faziam um vôo circular sobre a área onde os golfinhos estavam e realizavam um mergulho ("Plunge divers"; $c f$. NELSON, 1980).

Houve momentos em que grupos grandes de atobás (de 20 a 30 indivíduos) permaneciam boiando no mar. Esporadicamente, um indivíduo ("batedor") começava a voar pela região a diferentes altitudes, retornando posteriormente. Quando o atobá que estava voando encontrava golfinhos em atividade de caça em grandes grupos, realizava também um mergulho em direção ao cardume que estava sendo arrebanhado. Com a atividade de mergulho do batedor, os demais atobás também voavam em direção ao cardume arrebanhado pelos golfinhos e começavam a pegar peixes (Fig. 3a). Durante esta atividade de caça, como muitos dos peixes arrebanhados estão próximos à superfície, alguns atobás pemanecem boiando e predando sem a necessidade de mergulhar (Fig. 3b).

Fragata. Também foram comuns as associações entre as fragaras e os golfinhos podendo, assim como ocorre com os atobás, serem utilizadas o ano todo enquanto são executadas as três estratégias pelos golfinhos. Em nenhuma ocasião observei mais de duas fragatas utilizando os peixes arrebanhados. A estratégia utilizada foi sempre a de pairar sobre o cardume e apanhar os peixes da superfície ("Surface feeding whilst flying", $c f$. NELSON, 1980) (Fig. 3c). Nunca permaneciam associadas com os golfinhos por longos períodos.

Trinta-réis. Foram observadas durante o inverno, período em que migram do sul da América do Sul para a região de Cananéia. Apesar dos bandos numerosos (mais de 500 indivíduos), particularmente na Ilha do Cardoso (Fig.1), foram raros e pouco freqüentes os animais avistados em associação com golfinhos, variando em número de um a sete indivíduos. Grupos de uma a três aves foram observadas acompanhando e tentando pescar junto a uma pequena formação familiar de golfinhos em caça cruzada. $\mathrm{O}$ grupo de sete indivíduos foi avistado quando os golfinhos executavam a caça em grandes grupos, sendo a tática empregada para apanhar o peixe semelhante à utilizada pelas fragatas.

Gaivota. Como no caso dos trinta-réis, ocorrem somente no inverno e com poucos indivíduos. Comumente permaneciam pousadas nas praias, em pequenos agrupamentos de até oito indivíduos. Associavam-se aos golfinhos somente durante a caça em grandes agrupamentos, sendo a pesca semelhante à executada pelas fragatas e trinta-réis. Em alguns períodos também boiavam e 
pescavam os peixes que estavam na superfície, semelhante ao comportamento já descrito para os atobás.

Biguá. Foi observada somente um ocasião de associação entre um biguá e uma formação familiar em caça cruzada, no verão. Durante a interação, quatro biguás realizavam um deslocamento próximo à superfície do mar (cerca de 2 metros), até que encontraram os golfinhos caçando e então, apenas um deles iniciou mergulhos do tipo usado pelos atobás, mas por um curto período de tempo.

Associações multiespecíficas. Em algumas das ocasiões em que os golfinhos estavam em caça cruzada ou caça em pequenos grupos, houve rápidos períodos de associação entre atobás (no máximo de 10) e fragatas (geralmente duas), onde a maior atividade foi dos atobás. Quando a estratégia utilizada pelos golfinhos era a caça em grandes grupos, verifiquei a presença de até 30 atobás, duas fragatas e oito gaivotas. Novamente a maior atividade foi dos atobás. Duas vezes, após os atobás abandonarem a área de pesca, houve o aparecimento dos trinta-réis (sete indivíduos) que afastaram-se tão logo os atobás reapareceram.

\section{DISCUSSÃO}

Conforme já foi relatado por MONTEIRO-FILHO (1991), o repertório comportamental dos golfinhos $S$. brasiliensis na região de Cananéia, é complexo durante as atividades de caça. Na maioria das estratégias utilizadas a finalidade provável é dividir o cardume, desorientando os peixes e assim facilitando a captura de alguns indivíduos pois, segundo MAJOR (1978), com a diminuição do cardume aumenta a possibilidade de um indivíduo ser capturado. Desta forma, os comportamentos de caça cruzada e caça em pequenos grupos podem levar a uma desorientação de pequenos cardumes propiciando qua na fase final de cada seqüência de comportamentos, os golfinhos atuem independentemente durante o ataque, processo este que é bem conhecido para diversos peixes predadores de médio e grande porte (POTTS, 1983).

Com a caça em grandes grupos, verificamos que ocorre o contrário, havendo a manutenção da estrutura do cardume e esforços simultâneos dos membros do grupo de golfinhos, atuando um de acordo com os outros. Tal atividade caracteriza uma caça comunitária (CURIO, 1976), ou seja, alguns animais permanecem na periferia do cardume de presas mantendo-o coeso enquanto os outros caçam. O posicionamento dos golfinhos em relação ao cardume de presas é provavelmente alterado para que todos os animais envolvidos na tática possam se alimentar.

Quanto aos comportamentos executados pelas diferentes espécies de aves aqui relatados, parecem se comuns (NELSON, 1980), contudo, as associações com os golfinhos, não.

De maneira geral, as associações que envolveram golfinhos em caça cruzada e caça em pequenos grupos sobre pequenos cardumes foram utilizadas por poucas aves, cujo encontro era aparentemente ocasional, pois as aves que voavam à pouca altitude só poderiam localizar os golfinhos e conseqüentemente 


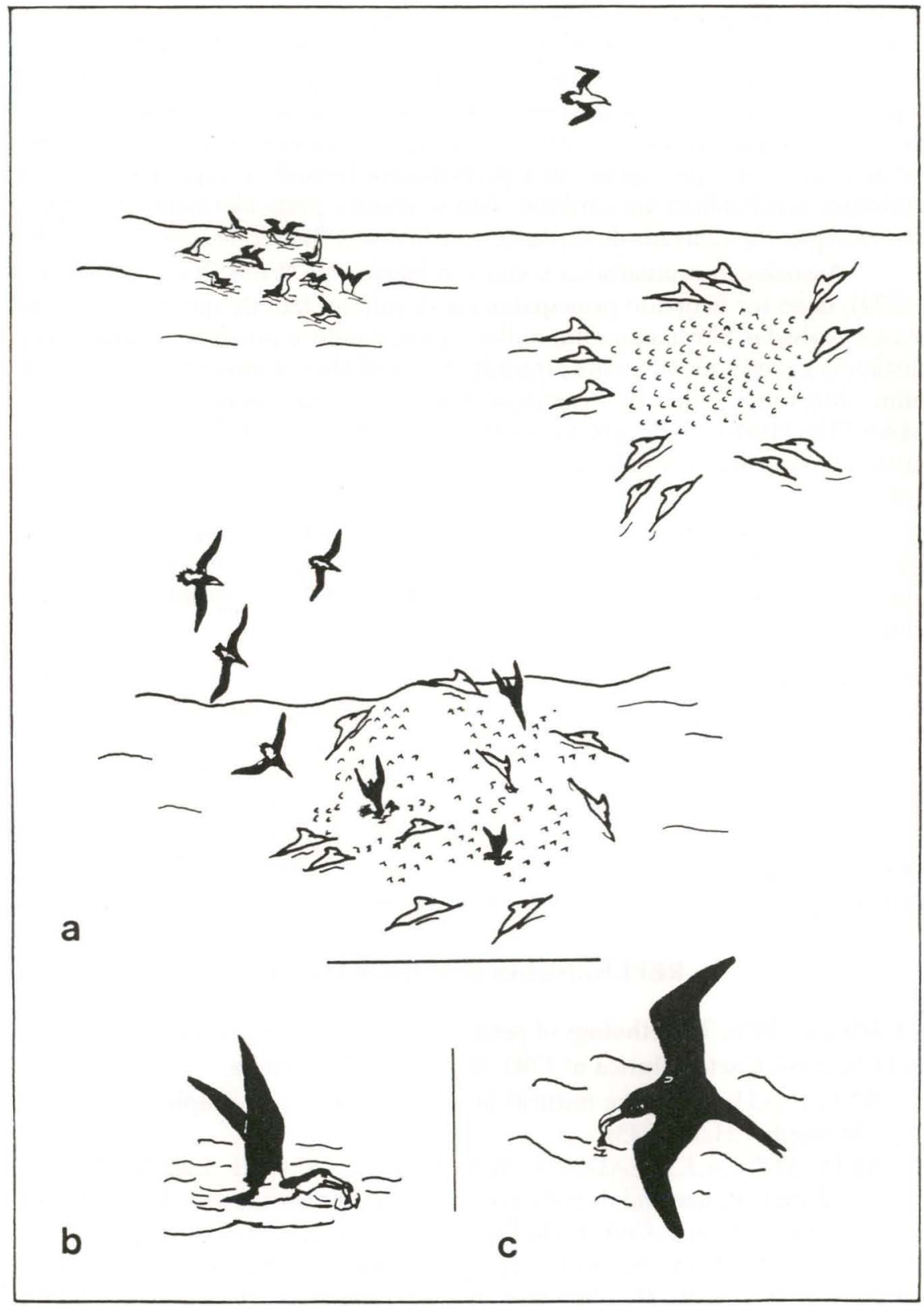

Fig. 3. Comportamentos utilizados pelas aves marinhas durante a atividade de caça. (a) Atobás permanencem boiando enquanto um batedor procura golfinhos arrebanhando um cardume, para então começarem a se alimentar; (b) em algumas ocasiões, aves boiando na área do cardume arrebanhado também pegam peixes. (c) fragata predando um peixe na superfície. 
o cardume a pequenas distâncias. Por outro lado, quando a caça dos golfinhos é feita em grandes grupos sobre grandes cardumes, toda a atividade é possível de ser localizada à distância, propiciando a aproximação das aves, tanto de espécies isoladas como em grupos mistos. Há contudo uma estratégia utilizada pelos atobás que parece estar associada à caça em grandes grupos e de maneira intencional, visto que muitas aves permanecem boiando e esperando que os golfinhos arrebanhem um cardume. Isto se verifica particularmente durante $o$ inverno quando a entrada de cardumes em direção à Baía de Trapandé é grande.

Associação mutualística como a relatada por WÜRSIG \& WÜRSIG (1979), deve ter ocorrido principalmente devido ao fato de que o número de aves envolvidas ultrapassou um milhar, aumentando a possível visualização à distância e conseqüentemente atraindo mais golfinhos. Entretanto no caso por mim observado, o tipo de associação parece ser semelhante ao relatado por MARTIN (1986), onde grupos com até 50 aves se beneficiam sempre da atividade de caça dos golfinhos, não havendo aparente benefício para estes golfinhos.

Portanto, assim como foi relatado para outros Delphinidae do Atlântico Norte (MARTIN, 1986), no sul do Estado de São Paulo o tipo de associação entre $S$. brasiliensis e pelo menos cinco espécies de aves marinhas é do tipo comensal, sendo as aves as únicas beneficiadas.

AGRADECIMENTOS. Agradeço aos amigos Euclydes R.A. Dias e Cyra A. Dias, ambos do Instituto de Pesca, pelo incansável apoio e paciência quando de meus trabalhos em Cananéia. A Francisco C. Soares e demais funcionários do Instituto de Pesca de Cananéia pela ajuda e importantes informações sobre a dinâmica das condições de clima e mar que ocorrem na região. À Mariluce Messias pela ajuda no campo. Ao Sr. Horário de Silva e demais pescadores da Ponta da Trincheira pelas orientações dadas de como trafegar sob diferentes condições de mar na região. À Karin D. Kempers por todo apoio, leitura do manuscrito e valorosas sugestões.

\section{REFERÊNCIAS BIBLIOGRÁFICAS}

CURIO, E. 1976. The ethology of predation. Berlin, Springer-Verlag, 250p.

D.H.N. 1987. Carta Náutica nº 1703. Ministério da Marinha.

EVANS, P.G.H. 1987. The natural history of whales and dolphins. London, Christopher Helm, 343p.

GASKIN, D.E.; A.J. READ; P.F. WATTS \& G.J. SMITH. 1985. Population and dispersal, size and interations of harbour porpoises in the Bay of Fundy and Golf of Maine. Can. Tech. Fish. Aquat. Sci. 1291: 1-28.

LAMB, F.B. 1954. The fisherman's porpoise. Nat. Hist. N.Y. 63 (5): 231-232.

LEHNER, P.N. 1979. Handbook of ethological methods. N.Y., Gaelan STPN Press, 430p.

MAJOR, P.F. 1978. Predatory-prey interactions in two schooling fishes, Caranx ignobilis and Stolephorus purpureus. Anim. Behav. 26: 760-777.

MARTIN, A.R. 1986. Feeding association between dolphins and shearwater 
around the Azores Island. Can. J. Zool. 64: 1372-1374.

MONTEIRO-FILHO, E.L.A. 1991. Comportamento de caça e repertório sonoro do golfinho Sotalia brasiliensis (Cetacea: Delphinidae) na região de Cananéia, Estado de São Paulo. Tese de Doutorado, não publicada, Universidade de Campinas, Campinas.

NELSON, B. 1980. Seabirds, their biology and ecology. London, Hamlyn, 224p. POTTS, G.W. 1983. The predatory tatics of Caranx melampygus and the response of its prey, p 181-191. In: P.L.G. NOAKES et al. (ed.) Predators and prey in fishes.

WÜRSIG, B. \& M. WÜRSIG. 1979. Day and night of the dolphins. Nat. Hist. N.Y. 88: 61-68.

Recebido em 02XI.1992; aceito em 07.VI.1993. 